\title{
INSTITUTIONAL SHAPING OF CULTURAL MEMORY: DIGITAL LIBRARY AS ENVIRONMENT FOR TEXTUAL TRANSMISSION ${ }^{1}$
}

\author{
Marija Dalbello ${ }^{2}$
}

The emerging trends in digital(ized) collection development from 1997 are examined using a sample of projects accessible through Web-based registries of the Association of Research Libraries and the Digital Library Federation. The analysis focuses on thematic repertoire, narrative structuring, underlying historiographic principles, presentation, and the context of institutionalization, combining empirical and interpretive approaches to understand how digital libraries are involved in the production of knowledge and how memory institutions are currently shaping this record in the digital environment. Digital collections are presently showcasing material previously restricted to scholarly uses, making it available for broader educational purposes. Nevertheless, they resemble the sixteenth- and seventeenthcentury Cabinets de curiosités in their limited ability to support scholarship or address information needs of defined communities of users. Programmatic statements for developers in the conclusion of the study suggest ways for improving the usability of these emerging textual environments, while recognizing new uses for the collections.

The authenticity of a thing is the essence of all that is transmissible from its beginning, ranging from its substantive duration to its testimony to the history which it has experienced. Since the historical testimony rests on the authenticity, the former, too, is jeopardized by reproduction when substantive duration ceases to matter. And what is really jeopardized when the historical testimony is affected is the authority of the object. One might subsume the eliminated element in the term "aura," and go on to say: that which withers in the age of mechanical reproduction is the aura of the work of the art. This is a symptomatic process whose significance points beyond the realm of art. One might

1. I would like to thank the following individuals for reading drafts of this article and offering useful suggestions: Heike Schimkat, Tefko Saracevic, Jana Varlejs, and the reviewers. I would also like to thank Dorit Ayalon for bringing to my attention the ARL Web registry.

2. Assistant professor, Rutgers-The State University of New Jersey, Department of Library and Information Science, 4 Huntington Street, New Brunswick, NJ 08901-1071; Telephone 732-932-7500/8215; Fax 732-932-2644; E-mail dalbello@scils.rutgers.edu.

[Library Quarterly, vol. 74, no. 3, pp. 265-298]

(C) 2004 by The University of Chicago. All rights reserved. 0024-2519/2004/7403-0002\$10.00 


\begin{abstract}
generalize by saying: the technique of reproduction detaches the reproduced object from the domain of tradition. By making many reproductions it substitutes a plurality of copies for a unique existence.

(Walter Benjamin [1, p. 221])
\end{abstract}

Digital collections rely on a technology for the multiplication of texts more extreme in its effects than the photographic reproduction that fascinated Walter Benjamin in 1936 when he wrote the essay from which the epigraph is taken. For Benjamin, a reproduction is a decontextualized object that loses its "aura," a unique presence in time and space that roots the object in a tradition. The textual tradition from which an information object emerges is retained through contextual processing and tools for managing collections in the context of the traditional library. Digital libraries provide an environment for the textual transmission of digital representations of paper-based collections and digitally born information. At present, libraries are experimenting with methods of contextual processing by which representations of information objects in the digital library are transformed into meaningful cultural texts. This process is marked by a high degree of uncertainty, propelling institutional change and change in the organizational field of librarianship.

Borrowing from Anthony Giddens and Christopher Pierson [2, 3] and an application of Giddens's ideas in the study of institutional change [4], it is possible to theorize digital library development in terms of structuration theory. In the emerging area of institutional operation, such as digital library development, the movement toward homogenization is driven by dominant paradigms, as hypothesized by Paul DiMaggio and Walter Powell in their work on organizational theory and organizational diversity [4, p. 148]. Moving from diversity in approach and form to homogenization driven by issues of legitimacy determined by the most dominant players in the organizational field hypothetically describes the current process of change in the organizational field of librarianship, which is moving from diversity and experimentation to isomorphism and homogenization. Digital librarianship is still a field "characterized by a high degree of uncertainty, [and] new entrants in the field, which could serve as sources of innovation and variation, [seeking] to overcome the liability of newness by imitating established practices within the field" [4, p. 156]. Therefore, the innovation processes will encounter resistance or attempt to conform to the legitimate (established) practices.

In understanding the emergent institutional forms related to digital librarianship, this analysis uses a sample of collections that emerged in the 
first five years of the digital library boom, from 1997 to 2002. By sounding these developments against a theoretical framework, this article demonstrates that this development is not merely a mass of microlevel activity, but one in which human agency and social structure are related, and in which the repetition of the acts of individual agents reproduces the structure [5]. Therefore, while observing institutional change through an empirical study, using a middle-range theory of structuration, this study also looks at digital libraries as emerging environments for creation of cultural texts and cultural selection, thus engaging also a macrosocial theory of the dynamics of cultural change [6]. On that level, collection building (1) is a form of knowledge creation and interpretation of textual tradition and (2) reflects the transformation of the library as memory institution in the context of modernity; it operates increasingly in representational fields, simulacra rather than physical documents. The classic literature on social memory and cultural heritage recognizes the agency of institutions and technologies of reproduction in shaping cultural memory [7-13]. It also demonstrates the dynamic nature of cultural change in which institutional memory processes are characterized by invention within constraints of legitimacy defined by present concerns of social groups [14-18]. The shaping of cultural memory corresponds to the emergence of shared narratives from an array of possible historical interpretations. Loci of memory, key events, key texts, or artifacts then become symbolic points of reference for group identities [19-20]. Digital libraries represent textual environments in which the formation of the emergent memory narratives as collections of representations of memory objects and information arranged according to historiographic principles occurs. In studying digital libraries from a macrosocial theory point of view, we need to take into account the frameworks for analysis provided in the literature on the study of cultural memory and identity [10,19] and history as cultural invention [14]. In the first wave of digital library development, one primarily finds digitized libraries that provide continuity for existing collections. Thus, they are involved in interpreting the past through historical representation.

Studying how digital libraries are involved in the production of knowledge is crucial to our understanding of how memory institutions are currently shaping this record in the digital environment. The implications for that understanding are far-reaching because the traditional role of memory institutions in shaping a society's view of its own identity, of its heritage and its past, has been at the center of the arguments concerning those institutions' legitimacy. With the changing technology, the institutions are also undergoing transformation in terms of rethinking their collections, users, and access. This study provides an insight into this process, focusing on the efforts of library practitioners. I examined digital library projects listed by the Association of Research Libraries (ARL) and the Digital Library Fed- 
eration (DLF). ${ }^{3}$ They represent the efforts by leading research libraries in the development of digital collections. ${ }^{4}$

The processes of homogenization may be hypothetically assumed to follow in the aftermath of the initial stage of the life cycle of digital librarianship examined here. In fact, some trends toward homogenization are already emerging in the period of the initial digital library boom. Methodologically, this implies that a longitudinal study of digital library development as field of innovation in the organizational field of librarianship is a logical next step and the continuation of this research. Nevertheless, this overview of trends and current directions in digital library development may be useful for practitioners in building collections. A set of statements focusing on the innovative aspects of the digital libraries that aid sustained and planned collection development is included in the conclusion.

\section{Methodology}

An organizational field as unit of analysis is defined by the similarity of services or products provided [4, p. 148]. The corpus for analysis is therefore defined in terms of organizational field in which individual agents are aggregated around digital library development. Because the goal was to recognize models of development, the unit of analysis was limited in terms of organizational activities. First, the focus of the analysis was on retrospective cultural heritage-oriented projects established in U.S. institutions. Second, content-creation activities in which libraries act as publishers of the material held in their own collections were considered, rather than associated services (electronic journals, electronic reserve). Digital projects in or involving libraries were identified through a metaresource index maintained by the ARL. The ARL Digital Initiatives Database [21] is a Web-based registry of digital initiatives. ${ }^{5}$ Although many of the projects included in this registry date from the early days of the World Wide Web or even predate it, most of them emerged after 1998. The ARL registry

3. In the United States, the DLF (formed in 1995) is an organization of research libraries and various national institutions. It is an organization that represents libraries and practitioners. The stated goal of DLF is to offer "information about developing digital collections and managing networked information for the benefit of scholarship, education, and cultural progress" (http://www.diglib.org/dlfhomepage.htm; accessed November 10, 2003).

4. The efforts of the practice community are separate from the efforts of the research community represented by the research projects supported by the first and second Digital Library Initiative (DLI); the latter are not analyzed here.

5. The ARL Web registry was established on the initiative of the University of Illinois at Chicago and the ARL, following the Preservation Committee meeting at the Fall 1997 ARL Membership Meeting (Dru Mogge, e-mail communication with the author, June 2, 2001). 
provides access for projects that reflect mainstream activities and gives detailed summaries of the projects. Although primarily focusing on libraries and archives in major research institutions, this registry also includes public and school libraries, although notably to a lesser degree; museums; historical societies; and other cultural institutions that form the landscape of memory institutions. Comparable with the ARL registry is the registry maintained by the DLF [22]. The two registries overlap significantly, with eighty projects-collections (all in the United States) listed in both databases; 592 (U.S.) projects are listed between the two of these registries. ${ }^{6}$ The projects are the public domain online digital collections.

The digital collections examined in this study (using the ARL registry) had the following characteristics:

- projects with "retrospective" orientation, that is, those dealing with cultural heritage,

- projects that have achieved some sort of institutionalization,

- projects in the public sector, and

- projects that represent the U.S. approach in dealing with cultural heritage.

The level of comprehensiveness of the ARL registry was considered adequate in meeting a research objective of establishing patterns and trends in U.S. research collections. Attempts to capture the state of the art of digitization projects dates from 1995 [23], when the Council on Library Resources and the Commission on Preservation and Access (CPA) conducted a joint survey of existing, in-progress, and planned activities, which were published by CPA [24]. The RLG DigiNews [23] lists ten similar attempts internationally, yet none of these has the same depth of coverage and scope. At this point, there is no comprehensive Web-accessible catalog of digitized collections available on the Internet, but ARL and DLF registries are not the only ones.

Although they represent a fraction of all efforts, these two registries are representative of overall trends, capturing a formative period in the development of the digital libraries by library practitioners. At least, this method made it possible to study systematically this emerging phenomenon, and it offers a quantifiable field of frequencies at a time when these institutions

6. Among the thirty institutions contributing to the DLF registry, all but one are in the United States. Bibliothèque Nationale (France) is the only international project listed. All but two (the New York Public Library and Atlanta South Gastroenterology, P. C.) are universities and colleges. Four projects involve collaboration by the Library of Congress and a university. While only seven institutions found in the DLF registry are not included in the ARL registry, eighty projects are listed in both registries (including four that are different versions of one project), amounting to 21 percent of the projects overlapping. Most of these projects (fifty-seven of eighty projects) are based in the Library of Congress. 
may be entering a consolidation stage in their digital development efforts. If 1997 is considered a milestone for many research libraries, it makes sense to look at digital library development in a five-year retrospective.

Of the 355 projects in the ARL registry institutionalized in U.S. institutions, three hundred are historical in nature. The remaining projects range from digital libraries capturing environmental information and repositories of technical reports to repositories of instructional materials. Even this cursory assessment shows that the digital library initiatives reported in the ARL registry maintain the dimension central to traditional memory institutions, that of preserving the record of the past. Therefore, the analysis focuses on the retrospective orientations of digital library projects. It also provides an insight into the institutional contexts for the interaction and negotiation of culture in the digital environment. Thus, it aims to give a partial answer to the question of how U.S. digital library projects in libraries are managing America's cultural memory.

The following research questions were formulated:

- How are institutional contexts shaping America's record of the past in the digital environment?

- Which base cultural references are used to shape an emergent memory narrative in the current projects, and how does that contribute to an overall narrative coherence of the emergent cultural text?

- How do the emerging digital libraries approach the presentation of knowledge?

Based on these questions, this study has formulated the research objectives as follows:

- Identify the institutional contexts for current digital library projects.

- Analyze content of existing projects and determine their subject focus, organizing metaphors and spatial-temporal devices as cornerstones of coherent networks of temporal, spatial, and causal relations between events in the story.

- Describe the nature of representations and existing techniques of contextual processing.

In addressing the first objective, the trends and patterns of change in the organizational contexts were identified to examine institutionalization processes (diversity vs. isomorphism). The second objective resulted in the analysis of content features, narrative tools, and organizing metaphors in current projects. The third objective resulted in the examination of representational techniques in current projects as they are related to the nature of the digital library as an extension of the library as memory institution in the context of modernity, operating increasingly in the representational fields of simulacra rather than physical documents. 
TABLE 1

Distribution of Digital Library Projects by Country

\begin{tabular}{lc}
\hline \hline Digital Library Initiative & No. of Reported Projects \\
\hline North American: & \\
Canada & 19 \\
United States & 378 \\
European: & 1 \\
Croatia & 14 \\
England & 2 \\
France & 1 \\
Germany & 2 \\
Hungary & 1 \\
Ireland & 2 \\
Netherlands & 2 \\
Scotland & 1 \\
Wales & \\
Other: & 7 \\
Australia & 2 \\
China (People's Republic) & 432 \\
$\quad$ Total & \\
\hline NotE. $-N$ = 432 projects listed in the Association of Research Libraries registry, excluding duplicates.
\end{tabular}

\section{Analysis}

Section II.A identifies trends of development in their institutional contexts in terms of innovation processes and homogenization forces. The projects are then analyzed in terms of content in Section II.B. Section II.C focuses on contextual processing and representational aspects of information objects in digital libraries.

\section{A. The Emerging Models of Development: Diversity and Isomorphism of the Organizational Field}

The contexts in which digital library projects emerged in the past five years define the nature of these collections, their user base, and eventually their impact. The projects are found in all types of memory institutions, from libraries to archives and museums. The projects are primarily located in the United States. Their geographic distribution is shown in table 1 and their institutional distribution in table 2.

Although digital library projects registered with ARL (432) are primarily from the United States (378), some of them are based in Europe, Australia, and China, as shown in table $1 .^{7}$ The highest number of U.S. projects in the

7. Although ARL registry cannot be assumed to provide sufficient coverage for international efforts, an interesting pattern emerges there as well. Notably, the data show that universities 
TABLE 2

Organizational Contexts for Digital Library Projects in the United States

\begin{tabular}{lr}
\hline \hline & $\begin{array}{c}\text { No. of } \\
\text { Organizational Context }\end{array}$ \\
\hline Digital Libraries \\
Library of Congress, Smithsonian Institution, National Ar- & 2 \\
$\quad$ chives and Records Administration, National Agricultural & \\
$\quad$ Library, National Library of Medicine & 91 \\
Universities (general collections) & 54 \\
Universities (special collections and archives) & 138 \\
Public libraries & 18 \\
Societies/subject-specific institutes & 6 \\
Publishers & 2 \\
Historical societies/archives/museums & 32 \\
Collaborative projects (distributed model of digital library, & \\
$\quad$ either regional or cross-national) & 25 \\
Gallery, bibliographic utility, school, and botanical garden & 4 \\
Other & 6 \\
\hline
\end{tabular}

NOTE. $-N=378$.

ARL registry is from the District of Columbia, with a high concentration of digital library initiatives in Virginia and California. The critical mass of projects is in the University of Virginia (fifteen) and the Library of Virginia (nine). Virginia Commonwealth University, Virginia Polytechnic Institute and State University, and Virginia Tech are contributing a number of projects as well. Both local past and national heritage are featured in many of these projects.

The U.S. projects are distributed among 139 institutions. The Library of Congress leads with the number of registered projects (seventy). The Smithsonian Institution (sixteen), the University of Minnesota (twelve), the University of California, Los Angeles (fifteen), and the University of Virginia (fifteen) are other institutions with significant numbers of projects. The remaining 250 digital projects are spread among 134 different institutions (two projects per institution on average). According to the DLF

and national libraries are the primary homes for digital library projects, with national libraries taking the lead in most countries, with the exception of England and to some degree Canada. Canada is the most diversified in terms of the variety of reported institutional contexts. In England, the universities seem to have a leading role (some as reported test beds for the "Hybrid Library of the Future"). It seems that the projects outside the United States $(N=53)$ are mostly in the government sector, either at the national libraries or archives (twelve in France, England, Canada, China, and Wales) or at the state level (four in Australia). Museums, archives, and historical or subject-specific institutes (six in Canada, Croatia, and Germany) are home for other projects, and seven independent projects are found in China, Scotland, England, and Australia. Universities are host to numerous projects in Canada, England, Ireland, and Scotland (twenty-three). 
registry, 373 (U.S.) projects in twenty-nine institutions make for an average of thirteen projects per institution. It is clear that the registries are limited if we know that large research libraries such as Rutgers University Library are currently running between fifty and sixty official projects, while represented by five projects in the ARL registry (and none in the DLF registry). Even though the registries are not comprehensive and only list projects officially released by these institutions, they are representative of trends in institutions leading the digital library development.

The ARL registry projects are found in eight distinct types of institutional contexts, shown in table 2. From national libraries and museums to institutions that serve as test beds for the Digital Library Initiative (DLI), projects are found in university and public libraries, special libraries developed by commercial publishers, historical societies, archives, and museums. A significant number of projects (twenty-five) are cross-institutional, involving collaboration at a regional or broader level. Digital library projects (194) are primarily located in the universities (over half of all projects). The national libraries house a quarter of the projects (the Library of Congress, the Smithsonian, the National Archives and Records Administration [NARA], the National Library of Medicine, and the National Agricultural Library), with the rest distributed in public libraries, historical societies, archives, and museums. There are two DLI projects in this registry.

The organizational contexts identified in table 2 have implications for the philosophies of development. Even in terms of numbers, the university libraries provide a critical mass that currently determines the overall direction for development of digital libraries. The established paradigms for these institutions determine both this approach to the presentation of material and what the collections are. The Library of Congress reflects a different philosophy of development, based on public access and emphasis on educational role. And finally, there are projects that provide a unique approach, emerging in the institutions outside the first two categories. The three approaches reflecting distinct ideologies of development are further analyzed in the following subsections.

Maintaining continuity: Antiquarian traditionalism.-The strong representation of universities (with special collections, rare books, and archives) as homes for emerging digital libraries has an important implication for their current development. This is particularly obvious when we examine more closely what is being digitized. Traditionally, these collections are focused on preserving archival integrity (of provenance), and they are traditional in their approach to collection development. Emerging digital libraries are often an extension of these institutions' initial purposes. When automatically applied, the systems that work in a paper-based environment may be detrimental for digital environments. The organizing principles for collections 
traditionally evolved around a genre or, more organically, documents brought together because they relate to personal or institutional activities. Even more often, special collections evolved through the systematic collection of resources with a focus identified by scholarship in that area. When these purposes are transferred to online collections, they take two forms: showcasing materials in the form of Web exhibits or preservation effort. Debates around digitization as a means of reformatting are not relevant for this analysis. Nevertheless, the two approaches that are influencing the existing digital library efforts are both fraught with problems. In showcasing material through Web exhibits, the material is reduced to emblematic functions but, overall, is without a scholarly value because it is disconnected from its original collections. Even when these online collections are extensive, the display and retrieval mechanisms are too crude and the size of these collections are insufficient to serve the traditional scholarly purposes of sustained, rigorous, and systematic research. The limited scholarly usefulness of digital collections should pacify nostalgic historians lamenting the loss of the paper artifacts.

A distributed library: Integration and collaboration.-Unlike archival and special collections in the universities, the Library of Congress demonstrates new approaches to collection development. The projects not only integrate materials from different collections at this institution, but some of them are developed in partnership with public libraries and universities, thus creating new uses for the existing resources. If this paradigm prevails, collaborative efforts could become standard practice in developing digital collections around a subject or a regional focus. This trend toward the consolidation of the collections, although noticeable, has not achieved critical mass. (Only twenty-five such initiatives are found in the registry.) In addition to the Library of Congress, the University of Virginia and other regional historical institutions in Virginia are building similar infrastructures capable of the integration of collections around a common purpose.

The living library: Tapping into community memory.-Public libraries, for example, the New Orleans Public Library, are promising new types of digital libraries because they show a trend of linking digital libraries to communities, thus reestablishing a democratic purpose of the library as traditionally conceived in U.S. society. Given their ample resources, these institutions could have a strong social impact by giving a voice to regional diversity and local communities. As yet, they are the least represented in this registry (with seventeen projects in six libraries), which is not only due to the limitations of ARL registry as the source for data collection, but also to an overall trend in development. Community memory projects such as the one established at Brandeis University, "A People's History: 1999," the 
Bridgeport Public Library's "Bridgeport Working: Voices from the 20th Century," and the Idaho Museum of Natural History's "Benedicte Wrensted: An Idaho Photographer in Focus," are unique in giving a voice to communities, as described here: "One of the goals of this exhibition has been to demonstrate the ways in which photographs, even those a century old, can be placed in historical context. Only $1 \%$ of the Wrensted images at the NARA were identified at the onset of the project. Once they were shown to the descendants at the Fort Hall Indian Reservation, the families of origin were discovered. Individual names were recovered from written records, and today $84 \%$ of Wrensted subjects have been identified" (from description of "Benedicte Wrensted: An Idaho Photographer in Focus," available at http://www.arl.org/did [last accessed June 31, 2001]).

In distinct ways, digital library projects in this category connect the collections of documentary materials to ongoing social purposes. In the example of the Idaho Museum of Natural History, a collection is reevaluated by a living community.

The analysis presented here shows that the organizational landscape of library initiatives is, as yet, limited to universities and leading national institutions that have largely defined the innovation processes in digital library development. This limits how digital libraries are serving the U.S. public. Although the Library of Congress and the efforts of some public libraries and museums are attempting to democratize these institutions, the digital library projects continue to extend digital continuity only for scholarly resources. They are unconnected to the public and limited as educational resources. Moreover, because they are extensions of existing institutions, they reproduce institutional definitions of collection types. These collections are not, as yet, integrated across formats, in terms of relevance to a particular theme or subject, and across institutional boundaries. The Library of Congress, with innovative approaches to the integration of collections from multiple contexts, and its Library of Congress/Ameritech competition, enabled cross-institutional collaboration. The political implications of the critical mass provided by the academic libraries so far have been somewhat negative because they promote paradigms valid for physical collections stored away in special collections and archives and intended for scholarly use. These institutions are an important source of isomorphism in the organizational field. DiMaggio and Powell postulate that isomorphism is driven not by efficiency but perceived legitimacy [4, p. 152] as defined by the dominant players in the organizational field. We may hypothesize that the ability of university libraries to diffuse their model rests on advanced technologies for digital library development coupled with the legitimacy of university specialists as innovators. Yet, the usability of these online collections does not extend the original mission of these institutions. In order to extend the usability and relevance of networked collections, all institutional players in 
the field of digital library development should embark on redefining the status of a collection, recognizing its significance outside of task-related purposes and toward a more holistic concept of the library.

A comparison of American with international initiatives shows the emergence of digital library initiatives in the U.S. context as following a more distributed pattern. It is not surprising to find a self-organizing, decentralized system with minimum central involvement characterizing the development of digital libraries in the United States. The limited evidence of projects in the ARL registry shows what is intuitively known-that their counterparts in Europe and Asia are evolving in a centralized, governmentdirected context. In the U.S. context, the strong tradition of academic institutions and the peculiar role of the Library of Congress, which is not a national library, determined the initial development of digital library projects. Without a cultural policy articulated by a given ministry of culture, projects are taking off in a variety of institutional contexts. Basically decentralized, digital libraries in the U.S. context also display a dynamic of cooperation and competition. Cooperation is evident in the pattern of collaborative, distributed digital libraries. Competition for grant money is implied even in this cursory examination.

This research could not establish the relative impact of each of these initiatives, most of which started between 1997 and 1999, although universities have built a critical mass already. It is not clear which among these initiatives will grow and at what pace; it is not possible to make statements of cultural impact based on the future rate of growth or the size of the collections. According to their self-definition in the descriptions of the projects, most of these projects are at "pilot" stage, or in their first or second release. This means that the next decade may bring about the establishment of more projects that are transinstitutional. This study captures digital library development barely a decade from the emergence of this new form. This is still a formative period for digital libraries, and, as this analysis shows, through normative pressures of university libraries, the further development of digital libraries could be defined in terms of a paradigm of the scholarly collection for the organizational field as a whole.

B. Building Narrative Coherence: Organizing Metaphors, Storytelling, and the Semantics of the Digital Library

Interpreting digital library projects as a unified cultural text structured as narrative starts from a premise that a unified metanarrative is possible. In essence, this position imagines the existing digital library projects as snippets from a unified body of knowledge constituted by memory institutions. It also works with the assumption that human agency and social structure are related and that the repetition of the acts of individual agents reproduces the structure [5]. Memory institutions have been the legitimate pro- 
ducers of culture and identity, the official repositories of common culture. They have a regulated (legitimate) and regulative effect (legitimating) in society. The fixed object orders of the past-in the museum, the archive, and the library-represent shared memories of a society. It is reasonable to consider digital libraries to be developing under assumptions of continuity, with the existing memory institutions maintaining and building shared memories. With these assumptions, the second research question focuses on the semantics aspect of digital library development, the content, organizing metaphors, and storytelling strategies that support narrative coherence of Web-based collections. In the Web environment, as much as in other textual environments, narrative coherence is achieved through construction of "a coherent network of temporal, spatial, and causal relations between events in the story" [25, p. 1].

The fixed orders presume an existence of a unified body of knowledge or discourse field. The ability to produce unified narratives depends on the ability to introduce "narrative coherence," that is, the presence of a storytelling process in which order is imposed on disjoined pieces of information and fragments of information become meaningful. Narrative coherence is established when it is possible to envision a set of events as belonging to the same order of meaning [26, p. 16]. Such organization of narrative by rhetorical figures, spatial patterns, or metaphor provides the link from the concrete (instantiations) to the abstract (universal), from a fragmented record to a unified record. The literature on narrative focuses on time and space as primary organizing principles of the narratives. Because narratives are symbolic structures (codes) that link particular events and existences to abstract and universal concepts, they have a potential for creating a cultural text from disjoined fragments. They are able to introduce external orders of meaning to events and to form the "subject" that imposes "a totality evolving in time" [26, p. 16] on a chain of events. Theorists of narrative consider narrative to be a strategy for making sense of life, telling a story, and making reality. The analysis presented here identifies some of the elements from which that reality is constructed in the digital library projects and how that reality reflects an emerging cultural record. This process is institutionally managed.

The analysis of content using titles and project descriptions reveals some trends in the subject focus, as shown in table 3. "Biography focus" is significant, with a quarter of the projects dealing with individual and collective biography (25 percent). This includes the history of organizations, firms, societies, and universities, as well as library and archival collections. If one adds projects that deal with the experience of particular ethnic groups (9.4 percent), we have as a single largest category of projects those focusing on the experience of individuals, of groups, or organizational memory. The "single topic project" is another significant type (21.1 percent). The 
TABLE 3

Subject Focus of Digital Library Projects

\begin{tabular}{|c|c|c|}
\hline Subject Focus of Digital Library Projects & $\begin{array}{l}\text { No. of } \\
\text { Projects }\end{array}$ & $\begin{array}{c}\text { Ratio } \\
(\%)\end{array}$ \\
\hline \multicolumn{3}{|l|}{ United States: } \\
\hline History (twenty-two projects): & & 7.4 \\
\hline Overviews of eras, key events, and social history & 2 & \\
\hline American Revolution (1775-83) & 2 & \\
\hline Civil War Era (1850-72) & 1 & \\
\hline U.S. Civil War (1861-65) & 1 & \\
\hline World War I (1914-18) & 0 & \\
\hline New Deal Era (1933-40) & 1 & \\
\hline World War II (1941-45) & 2 & \\
\hline Other events (U.S. history) & 13 & \\
\hline Biography (individual) & 19 & 6.4 \\
\hline Biography (collective) & 7 & 2.4 \\
\hline Organizations, firms, societies, and universities (history) & 30 & 10.1 \\
\hline $\begin{array}{l}\text { Library and archival collections (retrospectives, histo- } \\
\text { ries of specific collections) }\end{array}$ & 18 & 6.1 \\
\hline $\begin{array}{l}\text { Ethnic and immigrant communities (twenty-eight } \\
\text { projects) }\end{array}$ & & 9.4 \\
\hline General & 3 & \\
\hline African Americans & 15 & \\
\hline Hispanic Americans & 2 & \\
\hline Native Americans & 6 & \\
\hline Portuguese & 1 & \\
\hline Japanese and Jewish Americans (World War II) & 1 & \\
\hline Social and political movements & 12 & 4.0 \\
\hline $\begin{array}{l}\text { Historical treatment of various topics, including history } \\
\text { of the written word and print culture related to } \\
\text { the United States }\end{array}$ & 63 & 21.3 \\
\hline Cultural-historical geography and maps, 1847-1929 & & \\
\hline (historic panoramic images) & 8 & 3.1 \\
\hline Regional (natural history, urban and rural landscapes) & 38 & 12.8 \\
\hline Europe (forty-three projects): & & 14.5 \\
\hline History, intellectual history & 7 & \\
\hline Biography & 9 & \\
\hline Various topics (historical treatment) & 27 & \\
\hline Other areas (nine projects): & & 3.0 \\
\hline Africa & 2 & \\
\hline Brazil & 3 & \\
\hline Cuba (poster art) & 1 & \\
\hline India & 1 & \\
\hline Liberia & 1 & \\
\hline Puerto Rico & 1 & \\
\hline Total & 297 & 100.5 \\
\hline
\end{tabular}


topics range from animated film and asthma to presidential campaign memorabilia and streetcars (see app. C). "Cultural and historical geography" and "regional history" together account for 15.9 percent of all projects. Surprisingly, digital libraries dealing with historical periods according to conventional periodization are sparse ( 7.4 percent). Projects that deal with social and political movements similarly are also rare (4 percent).

Time and space are the determinants of the historical narrative. They are further analyzed in the following directions.

Time dimension.-Temporal experience may be structured around specific historical periods or events. In the analyzed material, time is conceptualized as process or as event. Often, event-based time is used to represent the process, and there are therefore two aspects of temporal treatment.

Time process: This is recognizable in biographical narratives about individuals, institutional histories, or retrospectives of particular library and archival collections (listed in app. A). The history of ethnic groups may fall into this broad category. Equally dominant are historical narratives featuring objects. Often, these objects are genres of documents, writing tools, and various aspects of print culture (a full list is given in app. B), ranging from autographs to blotters. Nevertheless, when put together, these "histories" do not contribute to an overall historical narrative. They are historical episodes on a varied scale shaped around a "historical object," ranging from histories of asthma, baseball, and the nineteenth- and twentieth-century everyday practices of U.S. Catholics, to histories of lighthouses, national parks, New Jersey women, quilts and quilt making, smallpox, space stations, streetcars, sweatshops, and wind instruments (for a list of projects, see app. C). The examined digital library projects prefer the concrete rather than analytical or abstract history, conceptualizing time as an evolving objectified category. Ways in which "concretization" is achieved vary. Typically, the project features a document genre (such as Revolutionary song sheets or commemoration of the World War I armistice, featuring contemporary political speeches); others deal directly with material culture (such as blotters, flutes, or fossils). Document orientation and, to a lesser degree, material culture orientation rather than concept orientation are indirect ways to address historical time.

Time event: This is a technique often subordinated to time-as-process. Typical are digital libraries telling stories about social and political movements (for a list of projects, see app. B), through episodic and exemplary treatment of events, presented as disconnected vignettes. A similar preference for event-based history, as shown in table 3, is also applied to conventional historical subjects. Among twenty-two projects in this category (listed in app. B), thirteen focus on what is identified as a single event. 
The conventional history events range from the year 1492 and the Alaska Yukon Pacific Exposition to the invention of the telephone and the Klondike Gold Rush.

The emerging digital libraries reveal a preference for the atomization of time using documents to represent a movement of time and the transformation of a chosen object or phenomenon (as in a museum), or by creating process narratives that are so narrow in scope that they can be told in concrete terms. This is seen in a number of projects that are built around an event.

Space dimension.-Significant among the emerging projects (15.9 percent) are those focusing on cultural and historical geography, regional history, environmental history, and projects that deal with natural history (projects in this category are listed in app. C). They are directly related to the spatialization of physical forms. Nature and material culture are used to represent space distribution. Spatial representations focus on cityscapes, landscapes, waterways, and coastlines. Documenting these narratives of space are panoramic images (e.g., the Oregon Coast) and historical maps and photographs (often featuring the work of a single photographer in a particular locale, which adds to the coherence of these narratives). The scale on which space is superimposed varies. While some of the projects feature urban landscapes (most of them of New York City, but also Pittsburgh and Philadelphia's Chinatown), others focus on the geography of rural places or on geological features. Some aspect of material culture-bridges, buildings, and various architectural subjects-is used as a spatial marker in many of these projects. In many cases, there is an overt environmental concern and celebration of the U.S. landscape, both historical and contemporary.

Most of the projects are American in focus. Only 17 percent of the projects (fifty-two of 297) cannot be considered as Americana. While Cuban poster art or South African posters may indirectly reflect U.S. concerns, others are simply the consequence of a long-term collection focus on rare books and special collections of European materials. Digital libraries documenting explorers (James Cook) or natural history (Charles Darwin's voyages) and collections focusing on European achievements in the book arts (e.g., a genre such as books of hours, belt books, or the history of medicine) are in that latter category.

Overall, the emerging memory narrative indicates that some themes (the loci of memory) are more common than others; they show particular patterns along the time and space dimensions. In terms of time dimension, the projects:

- Focus on time as event to encapsulate time as process 
- Objectify time through concretization (focus on transformation of an object)

Historical periods are reconstructed through genres of written record (document orientation). In terms of space dimension, the markers of space are either related to nature or to human intervention into nature. A large number of projects explicitly deal with regional history (12.8 percent). If seen in the light of the relatively low ratio of non-American content in U.S. digital library projects, one may conclude that localization is an important aspect of the existing projects. The focus on the U.S. experience is explicit and dominant in these projects. Additionally, a large number of projects are biographical or deal with organizational history or the experience of immigrant and ethnic communities. This defines the boundaries of the U.S. experience. In contrast, history conceptualized in terms of periods defined by wars and revolutions is given little attention. A trend toward the obscure and the forgotten rather than the mainstream is another trait of these projects. Overall, a regional over general historical orientation and a focus on popular culture forms, event-based history (bordering on the bizarre and scandalous in some cases), and nature as an organizing metaphor of space are the most explicit traits of these emerging collections. A focus on the particular rather than the general, on aggregation rather than analysis, are features of current projects. Projects listed in the category "historical treatment of various topics," including the history of the written word and print culture (Americana), are narrow in scope. Moreover, the projects are developed around the existing document collections, as closed systems determined by the scope of these existing collections. Providing continuity for existing resources, these online collections are selections aimed to maintain narrative coherence in relation to larger bodies of texts. The knowledge structures provided by existing collections are necessary to understand the new textual environments. Therefore, "a coherent network of temporal, spatial, and causal relations between events in the story" [25, p. 1] that enables interpretation of these texts is maintained only in a larger context of library collections. Section II.C examines trends in digital library initiatives in terms of relationships among information objects (or arrays of information objects), their representations in the context of a digital library, and techniques of online presentation. Both of these aspects are related to narrative coherence, that is, the usability of digital libraries as cultural texts.

C. Digital Libraries as Representational Fields, Story-Generation Systems

Narrative presentation techniques used in the current initiatives relate to the representations of information objects, to provenance, and to the level of technological sophistication in the delivery of online collections. 
Disengaged objects in search of narrative coherence: Display, then terminate.Hayden White uses examples of historical discourse to show distinctions of narrative coherence among various historiographical representations: annals, chronicles, and fully realized historical discourse.

[He considers the chronicle to be] a "higher" form of historical conceptualization and represents a mode of historiographical representation superior to the annals form because of greater comprehensiveness, its organization of materials "by topics and reigns," and greater narrative coherency. The chronicle also has a central subject - the life of an individual, town, or region; some great undertaking, such as a war or crusade; or some institution, such as a monarchy, episcopacy, or monastery. The link of the chronicle with the annals is perceived in the perseverance of the chronology as the organizing principle of the discourse, and this is what makes the chronicle something less than a fully realized "history." Moreover, the chronicle, like the annals but unlike the history, does not so much conclude as simply terminate; it lacks closure, that summing up of the meaning of the chain of events with which it deals that we normally expect from the well-made story. [26, p. 16]

It is possible to evaluate current digital initiatives in terms of the level of narrative coherence by using White's distinctions. For example, projects encapsulated in some storytelling device are more likely to encompass disjointed, fragmented units of information itemized in various interpretations of the objects. Reliance on biography as a unifying technique, as I have shown, contributes to narrative closure. Here, the focus is on purely formal features of these projects and their implication for the level of narrative coherence. Retrieving from databases and browsing tree structures do not offer closure and, in fact, do not present fully realized narratives (the "well-made story"). Similarly, bulleted lists or crude Web exhibit displays lack closure and comprehensiveness. They do not present an account but simply display and then terminate. Although efficient for information retrieval, database as a mode of delivery results in low narrative coherence, that is, it does not allow for contextual processing. Narrative intelligence researchers argue that design principles for systems of retrieval and interfaces for multimedia knowledge need to be based on what we know about oral storytelling traditions [27, p. 3]. Prototype interfaces for digital storytelling acknowledge the interactive nature of collections (audience as producer) and the central role of multimedia in supporting exploration of knowledge bases [28-31].

The developers of digital libraries present their own approaches to contextual processing, demonstrated by the analysis of the mode of delivery for digital library projects shown in table 4 . The common mode of delivery is a static display of the objects supported by some form of browsing method (80 percent); this display primarily falls into the category of the Web ex- 
TABLE 4

Mode of Delivery for Digital Library Projects

\begin{tabular}{lc}
\hline \hline Mode of Delivery & No. of Projects \\
\hline Static-browsable: & 193 \\
Web exhibits & 15 \\
Web exhibits (multimedia) & 1 \\
Portable document format documents (PDF) & 12 \\
Searchable: & 2 \\
Databases: & 1 \\
$\quad$ Bibliographic & 1 \\
$\quad$ Data & 18 \\
Geographic information systems (GIS) & 10 \\
Search engine & 2 \\
Other (including structured text) & \\
Other & \\
\hline Note. $-N=255$ projects for which this information was available; the projects include only \\
those that originate in the United States. For many of the projects, it is difficult to determine from \\
the existing descriptions of the projects whether the mode of delivery is by one means only or by \\
a combination of two or more means. This is a preliminary finding based on the descriptions of \\
projects.
\end{tabular}

hibit. Images and textual objects are most common with multimedia exhibits and moving images. Audio files represent a smaller fraction in the category of static digital libraries. Browsing is accomplished by means of hierarchical tree structures, alphabetic lists, and retrieval by recognition (from thumbnail images). Only one in five projects (14 percent) is delivered in a database, most commonly for indexed images. Other searchable features include digital finding aids, structured text, or databases served on the Web. Retrieval of documents tagged using Standard Generalized Markup Language (SGML) is rarely applied and usually only to small-scale text-editing projects.

Static display is a dominant mode of delivery for the digitized collections. The viewing experience is framed as a tour, an event that readers create for themselves. A viewing event that may be repeated many times is different each time, similar to an experience of viewing artwork. The description or instruction for use "does not reproduce the object, it rather helps us to re-stage and restate the effort" [32, p. 147). A description of the following digital library project describes such a protocol of viewing: "This exhibit is intended to document and celebrate that first broadcast, which you can view by clicking the middle icon below. The first and third links take you to biographical information about the Crawfords, articles written prior to or following the broadcast, and the descriptive guide of the Crawford materials available at the Archives. Choose from among these links to launch you on your tour" (http://www.wheaton.edu/bgc/ archives/crawford.htm [accessed May 13, 2001]). 
Without studying viewers, we cannot qualify the nature of viewing beyond the protocols implied in the collections themselves. Yet, there are fundamental changes in the nature of perception related to digital libraries that affect the nature of retrieval. We may borrow from the study of interaction between the art object and the spectator and study these viewings as performances that are present in the process of the recovery of objects from a structural display. Saying that libraries are "performative" is paradoxical because "performance's only life is in the present"; performance "cannot be saved, recorded, documented, or otherwise made to participate in the circulation of representations of representations," and once it does, it ceases to be performance [32, p. 146]. Because interaction is "performative," it is "resistant to the claims of validity and accuracy endemic to the discourse of reproduction" [32, p. 147]. Yet the process of retrieval of objects is tied to forgetting and to recovery; in that process the responsibility for reconstruction is assumed by the spectator.

Digitized originals. - The sources that constitute digital collections online date from the early American colonial days to the present. There are a number of documents from the Revolutionary Era (1750-89) and the American Revolution (1775-83), representing the bulk of eighteenthcentury materials; documents from the nineteenth century include those from the Civil War Era (1850-72), including the U.S. Civil War (1861-65). Best represented is turn-of-the-century material, especially from the 1860s to the 1920s. Among twentieth-century documents, a significant number are from the New Deal Era (1933-40), especially the materials emerging from the Works Program Administration and Federal Writers' Project materials. The material generated in World Wars I and II (1914-18 and 1941-45) is somewhat represented. The latest material is for online exhibits, featuring primarily the history of institutions. There are digital projects that feature broad spans and selections of material documenting "American history" or "American social history," usually covering the 1600s to the present. They are identified as separate categories in table 5. Among the projects listed in the ARL registry, over 81 percent (175) relate to and display digitized surrogates of documents from the Americana collections: the nineteenth- and twentieth-century documents are most numerous among them. The European material, alone or in combination with American material, is less typical. The U.S. digital library projects are featuring their Americana collections as a priority. The subject focus has already been discussed in relation to table 3 .

The types of originals selected for digital libraries include, not surprisingly, those best adapted for visual displays. Their distribution is shown in table 6. Images comprise the content of ninety-three collections, or 37 percent of all digital library projects. These projects feature exclusively 
TABLE 5

Digitized Originals, by Period

\begin{tabular}{lc}
\hline \hline Time Period for Original Documents Included in Digital & \\
Library Projects & No. of Projects \\
\hline Americana (United States): & \\
$\quad$ Eighteenth century & 2 \\
Eighteenth and nineteenth centuries & 31 \\
Nineteenth century & 47 \\
Nineteenth and twentieth centuries & 62 \\
Twentieth century & 5 \\
1600s-present & 3 \\
1700s-present & 5 \\
Material from various time periods & 14 \\
Other ("American history") & \\
European and American combined: & 1 \\
1492 & 1 \\
Fifteenth to twentieth centuries & 1 \\
1850; 1880 & 1 \\
Other & 22 \\
European & 7 \\
Other (Africa, India, Cuba, South America, etc.) & 6 \\
Miscellaneous materials & 14 \\
\hline
\end{tabular}

NotE. $-N=214$ projects for which information was available; the projects include only those that originate in the United States.

visual materials, including unspecified types of images or combinations of various image genres and, as a single largest category, photographs (as a sole focus of 15 percent of all projects). These are collections of historical photographs often featuring a photographer's work, many times in a particular locale (frequently, these are the urban landscapes of New York City and the western frontier). The digital libraries are presenting an unprecedented record of U.S. photography from its earliest days in 1836 and throughout the nineteenth century. Another significant category is the moving image, presented in numerous digital library projects featuring actuality films and documentaries, but also animation films. The documents of textual nature (both published and unpublished) are featured prominently (30 percent of the projects). In the category "combined media," which is the largest single category in this distribution, we find another trend taking shape, namely, the integration of various media (sound, image, moving image, and text). Although documents are the focus of the collections, we also find data collections and material culture featured in digital projects. The material culture includes objects such as costumes and accessories, blotters, artists' books, and painted artwork.

The opportunities that digital libraries afford us to combine collections in presenting "stories" and "culture narratives" are evident in what is being 
TABLE 6

Primary Information Object Types

\begin{tabular}{lc}
\hline \hline Primary Information Object & No. of Projects \\
\hline Material culture: & 4 \\
Artifacts & 1 \\
Artwork & 26 \\
Documents: & 4 \\
Images (unspecified type and combined): & 1 \\
$\quad$ Films (actuality, feature) & 38 \\
Animations & 10 \\
Photographs & 1 \\
Prints (broadsides, posters) & 1 \\
Postcards & 11 \\
Baseball cards & 1 \\
Maps & 25 \\
Cartoons & 24 \\
Manuscripts & 29 \\
Published texts (books, newspapers) & 1 \\
Selections and various documents & 4 \\
Microform (manuscript) & 5 \\
Sheet music & 44 \\
Sound recordings & 2 \\
Combined media & 11 \\
Fragments (autographs, vignettes, etc.) & 5 \\
Combination (of material culture and documents) & 4 \\
Other (bibliographic information, data banks) & \\
Unspecified & \\
\hline
\end{tabular}

NотE. $-N=252$ projects for which this information was available; the projects include only United States projects. The primary information objects all entail a physical embodiment; they all are artifactual in nature. However, it is useful to distinguish documents (published and unpublished) from material culture as a distinct kind of information object type. This distinction has so far defined a boundary between archive-library and the museum as a distinct type of memory institution. The distinction between published and unpublished, which defined the boundary of the archive and the library, also loses its significance in the digital environment.

practiced by the projects examined here. Yet, there is a lack of coherence, and the levels of sophistication are varied. The delivery modes for the collections show that we are still in the primitive stage of the development of digital libraries. Digital libraries grown around document genres reinforce traditional library practices based on format. In many instances, these are successful in highlighting how genre affected the communication medium tied to particular social groups or phenomena (see "An American Ballroom Companion: Dance Instruction Manuals, ca. 1490-1920" at the Library of Congress).

In Section II.C, the level of narrative coherence of the presentation system was considered by looking at the relationship of the image as representation (signifier) and the information object type (artifact, document, sound recording, or moving image) as signified. The level of technological sophis- 
tication in their presentation and retrieval from the system and the level of narrative coherence of the presentation system are the elements observed in this sample of projects. They are aggregations of digital images with little syntactic coherence. They resemble the sixteenth- and seventeenth-century Cabinets de curiosités (cabinets of curiosities). These museums displayed knowledge indiscriminately, reflecting the agency of individuals and not necessarily a unified cultural text. Such museums gratified learned curiosity and provided a site for "humanist scholars and their patrons for a wide variety of cultural endeavors, filling them to capacity with objects-books, manuscripts, paintings, sculptures, medals, scientific instruments, naturalia and exotica, the bric-a-brac of the learned world" [33, p. 161]. The trend of digital library projects combining documents in different media is paralleled by a trend of material culture objects and documents integrated in single-focus displays. In this context, we find documents and fabrics, natural history objects (fossils) and photographs, as well as statuary, flutes, and audio clips, all in the same thematic collection. The boundaries between published and unpublished or archive and library, decompartmentalization of collections identifiable in terms of genre, and distinctions between material culture and document collections, as well as objects and written records, have implications on the shifting of boundaries (ideological and institutional) between a library and a museum.

The trends in the emerging digital(ized) collections, in terms of thematic preference, the nature of originals, digital formats, and delivery, indicate the following:

- Period best represented: $1860-1920$

- Subject focus: Revolutionary War, Civil War, African-American experience, local history, natural history, history of technological inventions, architectural styles, musical forms, and evolution of print forms

- Originals: images, documents (published and unpublished), sound recordings, and artifacts

- Digital formats: primarily scanned images, but also formatted electronic text; multimedia, to lesser degree; and bibliographic information

- Delivery methods: Web exhibit, limited use of databases served on the Web

\section{Conclusion: The "Aura" Recovered?}

To the degree that the digital(ized) libraries enable contemplation of information objects disengaged from context-adding tools established in tra- 
ditional library collections, their analogy to the sixteenth- and the seventeenth-century cabinets of curiosities is valid. Nevertheless, as shown in the analysis of the semantic aspects of the digital libraries, the historiographic principles are not absent from these presentations. They are distinct from the traditional libraries in presenting information objects. At present, the strategies of contextual recovery of objects are crude and elicit what may be called picaresque voyages that allow for episodic engagement with the materials. For the most part, these collections of disjoined information objects have a narrow subject focus, built around document genre and focusing on event-based history. The integrity by which a collection is tied to a particular historical figure, event, or locality aids the process by which disjoined representations of information objects (as images, e.g., of the pages of a book) become devices for placing information objects in a meaningful context. The existing efforts exhibit somewhat conflicting tendencies, ranging between spasmodic and coherent narratives. The representational strategies improving and threatening narrative coherence are listed and discussed in turn.

The representational strategies improving narrative coherence are

- Categorical determination (category as organizing principle)

- Biographical approach (person as organizing principle)

- Event-based approach (critical incident as organizing principle)

- Commemorative (temporality as organizing principle)

The representational strategies threatening narrative coherence are

- Reliance on the picaresque and the episodic

- Self-reflexivity

- Focus on local history

- Emphasis on the "famous firsts"

- Positioning local content in a global environment

The strategies that improve the narrative coherence via topicality, biographical, and chronological treatment provide contexts for the viewer to process information. Often, explanation is given as guidance for the user of the collection.

For example, a Web exhibit focusing on Michigan lighthouses (Clarke Library) claims to offer multiperspective viewing, including (1) a general history of lighthouses in Michigan, (2) a detailed chronology of Michigan lighthouses, (3) a discussion of the lighthouse keeper's life, and (4) a bibliography of lighthouse sources within the Clarke Library. Examples of biographical treatment include a digital library devoted to persons, such as Al Capone, or the history of a firm, for example, the Boston Gas Company.

The event-based approach includes documenting the 1919 World Series baseball scandal involving the Chicago White Sox versus the Cincinnati 
Reds, reconstructing the historical event. The focus on "famous firsts," such as the October 9, 1949, Sunday evening broadcast that marked the birth of televangelism, is another strategy. The emphasis on the uniqueness and curiosity of the phenomenon often entails sensationalizing it for popular consumption. Often, the focus is commemorative. Examples are Cornell University's "The Triangle Shirtwaist Factory Fire" (March 25, 1911) and the Library of Congress's digital library project entitled "1492," as an ironic portrayal of an eventful year and the year as temporal marker. The description of pre- and postcontact America and the Mediterranean world assumes a cultural historical approach that does not give closure to that "event" of "discovery." Chronological organization of these online collections does not allow for deep critical perception of the phenomenon.

Picaresque, episodic treatment is inherent in the difficulty of presenting narrative in image (largely, the structural unit of the digital library projects at this time) as a feature of many of these projects. Other features of these online historical narratives include self-reflexiveness in their tendency to speak about the institution's own history or about local history. This strategy uses context to achieve narrative coherence, but there is a danger of such narratives being able to operate only within a "restricted" code, meaningful only for a limited viewer group. This focus on the local is exemplified in numerous cases, ranging from a focus on a university campus to a history of buildings to a local landscape. Examples include the history of Austin's Creeks in the city of Austin, Texas; "A Pictorial History of Duke University's Mascot, Blue Devil"; and the history of the Hofstra University campus.

The focus on origin is also seen in projects featuring founding documents or dealing with university founders (e.g., American University). Localized in cultural communities for which these projects are primarily aimed, these projects may not show an awareness of a broader audience for which they are now interpreting their collections. The term "glocal" is now used to indicate presentation of local content in a global environment. Finding solutions to this problem presents a challenge for digital libraries. It is related to the "aura" and authenticity identified at the beginning of this article. At present, digital libraries are creating memory by celebrating local heritage (of their collections). In the context of a traditional collection, the scholarly use of information objects is contextualized in an archive or special collections. These contexts provide frameworks for situated retrieval through conventions of scholarly communication. One may agree with Jacques Derrida that the "archive" (he uses the term broadly) is a context for transmission of texts. He says: "The archive has always been a pledge, and like every pledge, a token of the future. To put it more trivially: what is no longer archived in the same way is no longer lived in the same way. Archivable meaning is also and in advance codetermined by the structure that archives" [34, p. 18]. 
In the context of the globally accessible collection, the objects need to be firmly defined by their traditional uses and off-line world. Without firmly being rooted in the contexts of use and real communities, they run the risk of not meeting information needs either of real or virtual communities. The distinction between "the real" and the so-called virtual in the context of globalization processes has been increasingly questioned on a theoretical level, as has the way in which the two relate to virtual interaction patterns [35]. Tapping into knowledge bases of local subjects and the neighborhoods in which they are produced is central to empowerment, and knowledge to reproduce locality is rooted in such dynamic contact of people and technology [36, p. 181] in the global context. Digital libraries should become a site and agency for such knowledge production processes.

The local, the partial, and the fragmented natures of postmodern collections that we see emerging are at the same time a strength because they enable access to materials previously accessible only through the conventions of scholarly communication-the access to the historical record of everyday experience and multiple perspectives exemplified by projects such as the Library of Congress's featuring African Americans' experience of the Civil War. "Bridgeport Working: Voices from the 20th Century" documents everyday life, and the history of Philadelphia's Chinatown features oral history. This trend is promising for public libraries, which serve the largest populations, to extend their reach. A 1997 survey has shown that most large public libraries (serving between 50,000 and 100,000 persons) are responding in kind [37, pp. 48-49]. Bridgeport (Conn.) Public Library provides an example:

Fascinating stories about living in Bridgeport flowed like the waters of the Pequonnock River. Included were details of an ordinary person's daily life that gave insight into the past decades, moments that were hard to visualize for any newcomer to the City. What was it like to work and live in Bridgeport, Connecticut during the past century? Who else could tell us but people who worked on the line in the factories, sold goods behind the counter at a department store, taught children in the local schools, ran a travel agency, worked as a housewife, drove a truck, or ran one of the many other prosperous businesses that helped Bridgeport grow and develop. (Project Description: Bridgeport Working)

This study demonstrates that the emerging digital collections are not presenting sustained historical narratives in their presentation of material. This overall conclusion confirms a recent evaluation of the National Digital Library Initiative at the Library of Congress-that the result of the five-year digitization program is an impressive agglomeration of text and images but that the problem is in the delivery of narrative content [38]. Digital libraries springing up in various institutional contexts are as yet unconnected masses of fragments of data and visual information. In an analogy with the devel- 
opment of the museum, they are not unlike the collections of fascinating objects, the cabinet of curiosities of sixteenth- and seventeenth-century Europe. In a cabinet of curiosities, the assemblages of objects do not reveal a unifying narrative that contextualizes information objects within an authentic context of creation. They are meant to be places of incidental discovery and high viewer participation, but it is only ownership that unifies the clutter [33, p. 97]. Although they hold many educational promises, these collections do not provide an entry into the stories that can be recreated around these objects. For the academic libraries that are dominating the development of digital collections, the newly acquired educational role in the K-12 arena that access to previously closed collections of scholarly materials provides is a blessing in disguise. While the new uses for material can be seen as a positive development, the critics argue that such an expanded mandate is a wasteful use of resources. The efforts at showcasing the material for a broader audience, given the cost of digital conversion, infringe on the primary role of the academic library to meet the needs of the research community through sustained and planned collection development [39, pp. 58-59]. This statement corresponds with what was identified as the dominant trend in the organizational field of digital libraries: to create digital libraries as an extension of research libraries' initial purpose. According to that criterion, their deficiency is not a matter of principle, but a matter of degree. The current "working definition of digital library" by the DLF confirms the high value to the practice community of working within defined institutional boundaries and communities of users, and in recognition of institutional continuity: "[Digital libraries] are organizations that provide the resources, including the specialized staff, to select, structure, offer intellectual access to, interpret, distribute, preserve the integrity of, and ensure the persistence over time of collections of digital works so that they are readily and economically available for use by a defined community or set of communities" [40].

Definitions of user bases for digital libraries that correspond too rigidly to the traditional mission of the parent institutions are defined by dominant institutional leaders in the organizational field of digital librarianship for all institutional players. Narrowly defining the legitimate uses for the collections are not likely to encourage innovation in digital library development. In that model, the institutional players act as inert bureaucracies, placing the interests of the organization above efficiency and innovation. We should recognize that the new uses for digital libraries are likely to call for redefining usability, incorporation of narrative devices, and sensitivity for new and multiple uses for the collections that extend their scholarly purposes. The emphasis in future development of digital(ized) libraries would need to integrate the following agendas in the areas of technology, resources, organization, institutions, and use: 
Technology: University specialists as innovators need more awareness of the advances in the computer science field and of the efforts by individual developers that operate outside of the library context. Currently, the research and practice communities are operating in relative isolation from each other, as shown in a study of the dissemination of innovation in the digital library development by Tefko Saracevic and Marija Dalbello [41].

Resources: Determine priorities for themes that are not driven by document type (collection, genre driven). Focus on format integration and sharing resources.

Organization: This encompasses representation, organization, operability, storage, and searching. The emerging digital libraries provide a narrow and episodic view of history. A number of projects are built around critical events. Even if that approach may be continued in the future, analytical views need to be incorporated in presentation. Contexts for the viewers to process information need to be presented together with the collections. Constructing these collections in reference to larger historical narratives and context of scholarship would improve their narrative coherence.

Institutions: In order to extend the usability and relevance of networked collections, institutional players in the field of digital library development need to nurture a broader view of user base and collections that are primarily task related (purposed for scholarship). They also should extend collection development in consortial arrangement and extend their service base through the involvement of academic, public, and school libraries to optimize uses for the collections.

Use: This encompasses functionality, access, user communities, and related applications. Digital libraries need to be conceptualized as learning environments in which multiple perspectives of objects can be represented and multiple interpretations are possible. Digital libraries should integrate user perspective through annotation and commentary, and they should connect collections to communities.

These programmatic statements in the areas of technology, resources, organization, institutions, and use do not offer any solutions. Since the process of digital library development is in its initial phase, it provides an opportunity to exploit fully the potential of the new medium for shaping the textual canon and providing access to information to a broad constituency of users. In order to accomplish that goal, librarians need to make bridges to the developers working in other organizational fields and be aware of the benefits of diversified and experimental approaches in their own field. 


\author{
Appendix A \\ Biography (Americana) \\ Leonard Bernstein (1) \\ Al Capone (1) \\ Albert Einstein (1) \\ Abraham Lincoln (2) \\ Dolly Madison (1) \\ Thomas "Tip" O'Neill (1) \\ Linus Pauling (1) \\ Helen Quirini (1) \\ James Whitcomb Riley (1) \\ Andrei Sakharov (1) \\ Evelyn Scott (1) \\ Alfred Stieglitz (1) \\ Lorado Taft (1) \\ Benjamin Trueblood (1) \\ Angelica Van Buren (1) \\ George Washington (1) \\ Walt Whitman (1) \\ Ruth Young (1)
}

Collective Biography (Americana)

William Burroughs and Allen Ginsberg (1)

Football champions (1)

Founders (American University) (1)

Hayden pioneer biographies (1860-70) (1)

Presidents' and first ladies' portraits (1)

\author{
Biography (European) \\ Charles Babbage (1) \\ Lewis Carroll (2) \\ James Cook (1) \\ Charles Darwin (1), also see Darwin's voyage in various topics \\ (historical treatment) \\ Giuseppe Garibaldi (1)
}


Appendix B

Social and Political Movements

American radicalism and student movements (1)

Anarchism (2)

Conservation movements, 1850-1920 (1)

Student protests, 1970s (1)

Suffrage League of Virginia (1)

Televangelism (historical broadcast of 1949) (1)

Harlem Renaissance (1)

League of Nations (1)

American labor and industrial history (1)

Women's suffrage, 1848-1920 (1)

Workers in America, 1600-present (1)

American History-Events

1492 (Europe-North America) (1)

Alaska Yukon Pacific Exposition (1)

Alexander Graham Bell telephone invention, 1862 (1)

Capture of Fort William and Mary in New Castle, New Hampshire (image, depictions of) (1)

Chicago White Sox vs. Cincinnati Reds, 1919 World Series baseball scandal (1)

Commemoration of World War I armistice (1)

Coolidge Era mass marketing, 1920s (1)

Edison inventions (sound and motion pictures) (1)

Klondike Gold Rush (1)

William McKinley and the Pan-American Exposition, 1901 (1)

Brisbee Deportation, 1917 (an event from the labor movement history) (1)

Triangle Shirtwaist Company fire of March 25, 1911 (1)

\section{Appendix C}

Various Topics (Historical Treatment)

American foreign policy, twentieth century (1)

American theater (1)

American variety stage, $1870-1920$ (1)

Animated films (1)

Asthma (1)

Baseball (1)

Boston's Big Dig (1)

Daguerreotypes (Matthew Brady studio) (1)

Everyday life of American Catholics, late nineteenth century and twentieth century (1) 
Fashion (1)

Folk music-California (1)

Fort Valley music festivals (1)

Health advocacy (1)

Historic American buildings (1)

Japanese-American internment camps (Camp Harmony) (1)

Jesuits in Maryland (1)

Lighthouses (2)

National parks (1)

Nevada cattle ranching community (Ninety-Six Ranch) (1)

New Jersey women (1)

Pacific International Exposition (1)

Pain (1)

Presidential campaign memorabilia (1)

Quilts and quilt making (1)

Smallpox (1)

South Texas border, 1900-20 (1)

Space stations (1)

Streetcars, 1892-1940 (1)

Sweatshops in the garment industry (1)

Theater and costume design (1)

Tobacco industry (1)

Transportation network-Milwaukee (1)

Wind instruments (1)

Women's college education (1)

History of the Written Word and Print Culture (Americana)

America in caricature (1)

American founding documents (4)

Architecture in prints (1)

Armed services editions (1)

Autographs (1)

Baseball cards (1)

Blotters (1)

Brass music (1)

Children's books (1)

Georgia newspapers (1)

Illinois periodicals (1)

Political speeches, World War I and 1920s election (1)

Public land sale transaction documents (1)

Public opinion polls (1)

Religious petitions (Virginia, eighteenth century) (1)

Schoolbooks (1)

Sheet music (3)

Social dance manuals (1)

Song sheets (1)

American congressional documents and debates, 1774-1873 (1) 
Virginia newspapers (1)

Virginia's colonial history archive (1)

World War II American posters (1)

Regional History (Natural History, Urban and Rural Landscapes)

American buildings and landscapes (1)

American buildings and landscapes, 1850-1920 (1)

American West (1)

Appalachian (fiddle tunes) (1)

Architectural subjects (New York City, Florida), World's Fair, 1939-40 (1)

Arizona (river guides) (1)

Bay Area bridges (1)

Blacksburg, Virginia (1)

Bridgeport, Connecticut (1)

California (1)

California and Hawaii (1)

Champaign County, Illinois (1)

Chesapeake Bay (1)

Cleveland (1)

Colorado (1)

Georgia—history, 1930s (1)

Jamestown Settlement and the Virginia Experiment (1)

Maryland state records (1)

Mid-Atlantic small-town life (1)

New Jersey history (1)

New Orleans (1)

New York City (1), 1898-1906 (1), 1930s (1)

Oregon coast (1)

Park Forest community, Illinois (1)

Philadelphia's Chinatown (1)

Pittsburgh (1)

Rural and small-town America, 1880-1920 (1)

San Francisco (1)

Southern California (1)

Texas creeks (1)

Trans-Mississippi west (1)

Upper Midwest (1)

Virginia-buildings (1)

Virginia history (1)

Western Pennsylvania (1) 


\section{REFERENCES}

1. Benjamin, Walter. "The Work of Art in the Age of Mechanical Reproduction." In his Illuminations, edited by Hannah Arendt, pp. 217-51. New York: Schocken, 1969.

2. Giddens, Anthony. The Constitution of Society: Introduction of the Theory of Structuration. Berkeley: University of California Press, 1984.

3. Giddens, Anthony, and Pierson, Christopher. Conversations with Anthony Giddens: Making Sense of Modernity. Stanford, Calif.: Stanford University Press, 1998.

4. DiMaggio, Paul, and Powell, Walter W. "The Iron Cage Revisited: Institutional Isomorphism and Collective Rationality in Organizational Fields." American Sociological Review 48 (April 1983): 147-60.

5. Gauntlett, David. Media, Gender, and Identity: An Introduction. London: Routledge, 2002.

6. Wuthnow, Robert. Meaning and Moral Order: Explorations in Cultural Analysis. Berkeley: University of California Press, 1987.

7. Anderson, Benedict. Imagined Communities: Reflections on the Origin and Spread of Nationalism. 2d ed. London: Verso, 1991.

8. Douglas, Mary. How Institutions Think. Syracuse, N.Y.: Syracuse University Press, 1986.

9. Connerton, Paul. How Societies Remember. Cambridge: Cambridge University Press, 1989.

10. Lowenthal, David. The Past Is a Foreign Country. Cambridge: Cambridge University Press, 1985.

11. Butler, Thomas, ed. Memory: History, Culture and the Mind. New York: Blackwell, 1989.

12. Hamlish, Tamara. "Global Culture, Modern Heritage: Re-membering the Chinese Imperial Collections." In Museums and Memory, edited by Susan A. Crane, pp. 137-58. Stanford, Calif.: Stanford University Press, 2000.

13. Confino, Alon. The Nation as a Local Metaphor: Württemberg, Imperial Germany, and National Memory, 1871-1918. Chapel Hill: University of North Carolina Press, 1997.

14. Hobsbawm, Eric J. "Introduction: Inventing Traditions." In The Invention of Tradition, edited by Eric J. Hobsbawm and Terence O. Ranger, pp. 1-14. Cambridge: Cambridge University Press, 1983.

15. Fentress, James, and Wickham, Chris. Social Memory. Oxford: Blackwell, 1992.

16. Ong, Walter J. Orality and Literacy: The Technologizing of the Word. London: Routledge, 1982.

17. Vansina, Jan. Oral Tradition: A Study in Historical Methodology. Chicago: Aldine, 1961.

18. Zerubavel, Yaël. "The Historic, the Legendary, and the Incredible: Invented Tradition and Collective Memory in Israel." In Commemorations: The Politics of National Identity, edited by John R. Gillis, pp. 105-23. Princeton, N.J.: Princeton University Press, 1994.

19. Lowenthal, David. "Fabricating Heritage." History and Memory 10 (1998): 5-25.

20. Osborne, Brian S. "Locating Identity: Landscapes of Memory." Choice 40 (July-August 2002): 1903-11.

21. Association of Research Libraries Digital Initiatives Database. Available at http://www.arl.org/ did (last accessed July 1, 2002).

22. Digital Library Federation Public Access Collections. Available at http://www.hti.umich.edu/ $\mathrm{cgi} / \mathrm{b} / \mathrm{bib} / \mathrm{bib}-\mathrm{idx} ? \mathrm{c}=$ dlcoll $($ last accessed July 1 , 2002).

23. RLG DigiNews 4 (December 15, 2000). Available at http://www.rlg.org/preserv/diginews/ diginews4-6.html (last accessed July 1, 2001)

24. McClung, Patricia A. Digital Collections Inventory Report. Washington, D.C.: Commission on Preservation and Access, 1996. Also available at http://www.clir.org/cpa/reports/ mcclung/mccllong.html (last accessed December 20, 2002).

25. Persson, Per. "AGNETA and FRIDA: A Narrative Experience of the Web?" Available at http://citeseer.nj.nec.com/397404.html (last accessed November 10, 2003).

26. White, Hayden. The Content of the Form: Narrative Discourse and Historical Representation. Baltimore: Johns Hopkins University Press, 1987. 
27. Mateas, Michael, and Sengers, Phoebe. "Narrative Intelligence." In Proceedings AAAI Fall Symposium on Narrative Intelligence, pp. 1-10. Menlo Park, Calif.: American Association for Artificial Intelligence, 1999. Also available at http://citeseer.nj.nec.com/ mateas98narrative.html (last accessed November 9, 2003).

28. Don, Abbe; Teodosio, Laura; Lambert, Joe; and Atchley, Dana. "From Generation to Generation: Multimedia, Community and Personal Stories." In Proceedings of the Second ACM International Conference on Multimedia 1994, San Francisco, California, edited by Meera Blattner and John O. Limb, p. 337. New York: ACM, 1994.

29. Balabanovic, Marko; Chu, Lonny L.; and Wolff, Gregory J. "Storytelling with Digital Photographs." In Proceedings of the SIGCHI Conference on Human Factors in Computing Systems, April 2000, vol. 2, edited by Thea Turner and Gerd Szwillus, pp. 564-71. New York: ACM, 2000.

30. Cassell, Justine; Ryokai, Kimiko; Druin, Allison; Klaf, Jack; Laurel, Brenda; and Pinkard, Nichole. "Story Spaces: Interfaces for Children's Voices." In Proceedings of the ACM SIGCHI Conference on Human Factors in Computing Systems (CHI), edited by Marilyn Tremaine, pp. 243-44. New York: ACM, 2000.

31. Ellis, Jason B., and Bruckman, Amy S. "Designing Palaver Tree Online: Supporting Social Roles in a Community of Oral History." In Proceedings of the SIGCHI Conference on Human Factors in Computing Systems, vol. 3, edited by Jule Jacko and Andrew Sears, pp. 474-81. New York: ACM, 2001.

32. Phelan, Peggy. Unmarked: The Politics of Performance. London: Routledge, 1993.

33. Findlen, Paula. "The Modern Muses: Renaissance Collecting and the Cult of Remembrance." In Museums and Memory, edited by Susan A. Crane, pp. 161-78. Stanford, Calif.: Stanford University Press, 2000.

34. Derrida, Jacques. Archive Fever: A Freudian Impression. Chicago: University of Chicago Press, 1996.

35. Wittel, Andreas. "Ethnography on the Move: From Field to Net to Internet." Forum: Qualitative Social Research/Forum Qualitative Sozialforschung 1 (January 2000). Available at http://qualitative-research.net/fqs (last accessed December 20, 2002).

36. Appadurai, Arjun. Modernity at Large: Cultural Dimensions of Globalization. Minneapolis: University of Minnesota Press, 1996.

37. Scally, Patricia H. "Digital Technology Projects: Already Thriving in Public Libraries." Public Libraries 38 (January-February 1999): 48-50.

38. Committee on an Information Technology Strategy for the Library of Congress, Computer Science and Telecommunications Board, and Commission on Physical Sciences, Mathematics, and Applications. "LC21: A Digital Strategy for the Library of Congress." Washington, D.C.: National Academy Press, 2000.

39. De Stefano, Paula. 2001. "Selection for Digital Conversion in Academic Libraries." College E Research Libraries 62 (January: 2001): 58-69.

40. Digital Library Federation. Available at http://www.diglib.org/roles/surveyla.htm (last accessed November 9, 2003).

41. Saracevic, Tefko, and Dalbello, Marija. "Digital Library Research and Digital Library Practice: Do They Inform Each Other?" Unpublished manuscript, Rutgers-The State University of New Jersey, Department of Library and Information Science, 2002. Available at http://www.scils.rutgers.edu/ tefko/Saracevic_Dalbello_DLib_02.doc (last accessed November 9,2003$)$. 